Article

\title{
Analysis of the Water-Energy Coupling Efficiency in China: Based on the Three-Stage SBM-DEA Model with Undesirable Outputs
}

\author{
Meng Wang ${ }^{1} \mathbb{D}$, Caizhi Sun ${ }^{1,2, *}$ and Xueli Wang ${ }^{2}$ \\ 1 College of Urban and Environment, Liaoning Normal University, 850 Huanghe Road, Dalian 116029, China; \\ wm1012399003@163.com \\ 2 Center for Studies of Marine Economy and Sustainable Development, Liaoning Normal University, \\ 850 Huanghe Road, Dalian 116029, China; 376531665@163.com \\ * Correspondence: suncaizhi@lnnu.edu.cn; Tel.: +86-411-8425-8412; Fax: +86-411-8425-8390
}

Received: 25 February 2019; Accepted: 19 March 2019; Published: 27 March 2019

\begin{abstract}
Although the relationships between water and energy systems have been widely researched globally, such studies have not properly considered the coupling and driving mechanisms of the nexus between water and energy. Based on panel data from 30 Chinese provinces and cities, we used a three-stage Slacks-Based Measure model for Data Envelopment Analysis (SBM-DEA) to estimate the Water-Energy coupling efficiency in China from 2003-2015. Using the Stochastic Frontier Approach (SFA) regression model, we constructed an index of environmental factors that affect the Water-Energy coupling efficiency from the four aspects of resource environment, social environment, economic environment, and ecological environment. The results indicate that the Water-Energy coupling efficiency scores in most provinces in China are high and stable, and that the coupling efficiency of water and energy in China has a distribution pattern of northeast $>$ east $>$ west $>$ central. Compared to the results in the first stage of analysis, the efficiency values in the third stage (after removal of environmental and stochastic factors) were smaller, illustrating that the coupling efficiency of water and energy in China depends on a favorable external environment. In the sample period, we also found that the improvement of the resource and social environments was the most conducive way to improve the Water-Energy coupling efficiency. Overall, the management level of technological innovation in China still has some room for improvement.
\end{abstract}

Keywords: Water-Energy coupling efficiency; Three-Stage Data Envelopment Analysis (DEA); Slacks-Based Measure (SBM); Stochastic Frontier Approach (SFA); index system of environmental factors

\section{Introduction}

Water and energy security is not only related to the sustainable development of the social economy, but is also directly related to economic security, ecological security, and even national security. Sustainable development is an important area in which energy and water objectives interact. Two of the UN's Sustainable Development Goals (SDG) are related to improving access to energy and water: SDG6 aims to provide available and sustainable management of water and sanitation for all, and SDG7 aims to provide affordable, secure, sustainable, and modern energy for all [1]. At the same time, in the contexts of global population growth, climate change, and resource shortages, water and energy shortages and conflicts are impacting the world's economic pattern, political order, and environmental health. Therefore, it is vitally important for countries to study the connection between water and energy [2]. A Water-Energy framework was presented at the World Water Forum in 2012, and the World Water Day in 2014 released a report on water and energy, calling on governments 
to consider local water capacity when formulating energy development strategies [3]. At present, research on water and energy at home and abroad is more concentrated on the utilization of water resources in the process of energy development, including the development of traditional energy sources, the development of new energy sources, and the consumption of energy in the processes of water resources exploitation and utilisation.

In China, the problems of water and energy are reflected mainly in the increasing total and per capita demands for water and energy. Urbanization and pressing policy options for high energy and water consumption aggravate the tensions between the water and energy sectors $[4,5]$. Recently, water and energy have become an important bottleneck in China's sustainable development. The spatial distribution of Water-Energy resources has long been extremely uneven in China and will continue to exist in the foreseeable future. China's water resources are distributed mainly in the southeast, with a distribution pattern showing an east-west trend, while its energy resources are distributed mainly in the central and northern regions, with a distribution pattern showing a significant northeast-southwest trend. Water and energy distributions are extremely mismatched, and this mismatch is exhibiting a slow upward trend, that is not conducive to the comprehensive utilization of water and energy resources. Over the years, stochastic changes in water and yearly renewal of energy resources have not significantly influenced the spatial distributions of Water-Energy resources in China, and the mismatch of the spatial distributions of water and energy resources is expected to remain stable for a long time [6,7].

For sustainable development, due to the global demand growth being faster than the population growth and the rising impact of climate change, it is vital for all countries to research the nexus between water and energy. Current studies have not properly considered coupling and driving mechanisms for this nexus, nor formed a theoretical basis for assessing this system. In addition, policies and plans for energy and water are often developed independently, an approach that cannot achieve the coordinated and sustainable development of water and energy.

Water is needed for each stage of energy production, and energy is crucial for the provisioning and treatment of water [8]. The complex interrelationship between water and energy is mainly embodied in three segments (production, transportation, and consumption) and this interaction has been strengthened by the increased demand for water and energy from climate change, industrial development, and population growth. From an environmental point of view, Ait et al. [9] believed that one of the biggest causes of climate change is the burning of fossil fuels, and that climate change is creating uncertainty about the future of the water supply that may affect future long-term water and energy security through more acute Water-Energy relationships [10]. Describing the relationship between water and energy from a technical aspect, Tyler et al. [11] used GIS to combine a digital spatial dataset of thermal power plants with basic engineering principles, quantifying the water intake and energy consumption of cogeneration plants to predict the demands of thermoelectric plants. From the economic perspective, the main focus is on water prices, electricity price subsidies, and questions regarding tariff structures. For example, Corrado et al. [12] analyzed the need for water resources and energy in the Green Transformation Strategy of Bologna, Italy. Water and energy are the basic materials of society, and the implementation of related policies inevitably brings social impacts [13].

In the evaluation of water and energy, it is most common to construct a model for the relationship between water and energy and conduct a whole life-cycle analysis based on the water footprint [14]. In the model-building approach, the input-output model has been proven to be an effective analytical tool for investigating the economic pressures on resources and the environment, such as taking regional characteristics and sectoral differences into account and using a multi-region input-output model to account for ecological and water footprints [15]. In addition, water can be used as an integral part of energy models, and vice versa. Thus, Dale et al. [16] combined the Water Evaluation And Planning system (WEAP) with the Long-range Energy Alternatives Planning system (LEAP) to analyze water and energy use in Sacramento, California, for nearly 20 years. Because the physical flows of water and energy are hidden in economic trade, it makes sense to use the concepts of "virtual water" and "embedded energy" to discuss the use of water and energy in an economic system [16]. 
In China, a 2011 Central Document, "Decision to Speed Up the Development of Water Conservancy Reform", proposed optimizing the allocation of resources and called for the integration of resources, economics, and the environment $[17,18]$. Based on studies of the relationship between water and energy in foreign countries, Chinese scholars have researched the domestic situation in China [19]. Zhu et al. [20] analyzed the relationship between water and electric power in China's power production based on the theory of virtual water, finding that virtual water (which is transported by electricity) is transferred from inland areas with a shortage of water resources to coastal areas. Zhou et al. [21] measured the relationship between water and climate based on flow analysis, suggesting that optimizing urban water supply system cabinets can reduce energy demand and greenhouse gas emissions. Meanwhile, domestic scholars have used the input-output model to analyze the relationship between water and energy at different scales. For example, Duan and Chen [22] combined the input-output model and ecological network analysis to analyze the Water-Energy nexus in China's energy trade, finding that international energy trade could alleviate China's water shortage problem but also increase its energy dependence on other countries or regions. Based on this method, Wang and Chen [23] constructed an input-output model of the Beijing-Tianjin-Hebei region to explore the structural characteristics of water and energy and the interaction between departments in the urban group.

To summarize, such previous research has only selected relevant variables to explore, lacking comprehensive indicators of measurement for an objective system. This paper establishes a more scientific and comprehensive index system, using D-S theoretical data synthesis with the objective weight with the help of the Stochastic Frontier Analysis (SFA) to remove the interference of random and environmental factors. The traditional SBM-DEA does not account for the influence of environmental and random factors, which leads to deviation in calculating efficiency [24]. However, China is a country of vast territory and unbalanced regional economic development, so it is necessary to consider regional differences and the impact of random noise to evaluate the nexus of water and energy efficiency more accurately. To eliminate the influence of environmental and random factors, Fried et al. [25] proposed a three-stage Data Envelopment Analysis (DEA) model, using the Stochastic Frontier Analysis (SFA) proposed by Aigner et al. [26] to remove the influence of external environment and random error on efficiency. This allows the calculated efficiency to reflect the management level of the decision-making unit more realistically, such that the model can analyze the relationship between the input difference value and exogenous environment variables in stage 1 using the SFA model. The three-stage DEA method has been applied widely in the field of efficiency evaluation in China. For example, Zhang et al. [27] used this to show that environmental regulation had a significant impact on the efficiency of construction industry.

In this study, the three-stage DEA model and the Slacks-Based Measure (SBM) model were used to calculate the nexus of water and energy efficiency in China, with the four inputs (capital stock, employment personnel, water footprint, and energy consumption). The desirable output was GDP and the undesirable outputs were carbon emissions and the grey-water ecological footprint. Through constructing the three-stage, non-radial, non-oriented SBM-DEA and an index system of environmental factors, the efficiency in 30 Chinese provinces and cities was factually calculated and analyzed which is called the Water-Energy coupling efficiency. The influence of external environment on the input slack was also analyzed, and directions for improvement in the nexus of water and energy efficiency were determined. From the above, we believe this article does propose enough novel information in the application development of data envelopment analysis (DEA). Furthermore, there are enough practical contributions to the sustainable development of water and energy in this paper.

\section{Methodology and Data}

\subsection{Three-Stage DEA Model}

The three-stage DEA model mainly analyses and solves the problem through three stages. Fried et al. [25] pointed out that the traditional DEA model does not take into account the influences of environmental factors and random noise on the efficiency evaluation of the Decision-Making Unit 
(DMU) and discussed how to introduce environmental factors and stochastic noise into the DEA model, arguing that it is necessary to isolate these factors. In the model's three stages, the key question is how to eliminate the environmental factors and random noise in the second stage [28].

\subsubsection{Stage One}

In 1978, three well-known operational research analysts first proposed the DEA method, which was used to evaluate the relative effectiveness of the same department [29]. The traditional DEA includes models such as CCR and BCC and is input-oriented and output-oriented in the direction selection. However, Liu and Tone [30] pointed out that there were two problems requiring further study: (1) the BCC model does not have a unit invariant property and (2) information loss caused by the improvement of radial and non-radial aspects. Then, Tone [31] proposed a non-radial, non-oriented SBM, which overcomes the shortcomings of the traditional DEA and can measure slack improvement and the amount of non-ray redundancy.

$$
\begin{gathered}
\rho=\min \rho=\min \frac{1-\left[\sum_{n=1}^{N}\left(S_{n}^{x} / X_{k \prime n}^{t}\right)\right] / N}{1+\left[\sum_{m=1}^{M}\left(S_{m}^{y} / y_{k \prime m}^{t \prime}\right)+\sum_{i=1}^{I}\left(S_{i}^{b} / b_{k / i}^{t \prime}\right)\right] /(M+I)} \\
\text { s.t. } \sum_{t=1}^{T} \sum_{k=1}^{K} z_{k}^{t} x_{k n}^{t}+S_{n}^{x}=x_{k \prime n}^{t \prime} ; \\
\sum_{t=1}^{T} \sum_{k=1}^{K} z_{k}^{t} y_{k m}^{t}-S_{m}^{y}=y_{k^{\prime} m^{\prime}}^{t^{\prime}} ; \\
\sum_{t=1}^{T} \sum_{k=1}^{K} z_{k}^{t} b_{k i}^{t}+S_{i}^{b}=b_{k^{\prime} i^{\prime}}^{t^{\prime}}, \ldots, M ; i=1,2, \cdots \cdots, I
\end{gathered}
$$

Here, the objective function $\rho$ is the coupling efficiency of water and energy. There are $K^{*} \mathrm{~T}$ DMUs and three factors associated with each DMU, including inputs, good outputs, and undesirable outputs, as represented by the three vectors $x=\left(x_{1}, \ldots, x_{N}\right) \in R_{+}^{N}, y=\left(y_{1}, \ldots, y_{N}\right) \in R_{+}^{M}$, and $b=\left(b_{1}, \ldots\right.$, $\left.b_{N}\right) \in R_{+}^{I}$, respectively. The input and output value of the first $\mathrm{k}^{*} \mathrm{t}$ DMU at period $\mathrm{t}$ is represented by the vectors $\left(x_{k^{\prime} n^{\prime}}^{t} y_{k \prime m}^{t}, b_{k \prime l}^{t}\right)$. The vectors $\left(S_{n}^{x}, S_{m}^{y}, S_{i}^{b}\right)$ and $\left(z_{1}^{t}, \ldots, z_{k}^{t}\right)$ denote the input and output slack and the weight of $\mathrm{K}^{*} \mathrm{~T}$ DMUs at period $\mathrm{t}$, respectively. The objective function $\rho$ strictly decreases with respect to $\left(S_{n}^{x}, S_{m}^{y}, S_{i}^{b}\right)$, and the objective value satisfies $0 \leq \rho \leq 1$. The first $\mathrm{k}^{\prime} \mathrm{DMU}$ is efficient in the presence of undesirable outputs, if and only if $\rho=1$. If it is inefficient, i.e., $\rho<1$, efficiency can be improved by removing excess inputs and undesirable outputs and by increasing the inadequacy of desirable outputs.

In the first phase, two values are calculated: the preliminary DEA efficiency value, used for the comparison and analysis of the following links in Section 3.3., and the slack value of input, which is the dependent variable of the second stage.

\subsubsection{Stage Two}

In the second stage, the slack variable is assumed to reflect the initial inefficiency, which is composed of environmental factors, inefficient management, and statistical noise [32]. The main objective of the second phase is to decompose the slack variables into the above three effects by SFA regression, where the slack variables are used to regress the environment variables and the mixed error items [33]. In the second stage, the external environmental factors and stochastic factors are further removed, which results in DMU input redundancy by only management inefficiency [34].

Assuming that there are $\mathrm{p}$ observable external environment variables with $\mathrm{n}$ DMUs, each DMU has $m$ inputs, and the slack variables are decomposed into three independent variables containing environmental factors, stochastic factors, and management factors:

$$
S_{i j}=x_{i j}+X_{i} \lambda i=1 \ldots \ldots m, j=1 \ldots \ldots n
$$




$$
S_{i j}=f^{i} z_{j} ; \beta^{i}+v_{i j}+u_{i j}
$$

In addition, $S_{i j}$ represents the slack variable of input $i$ of DMU $j$ (i.e., the difference between the actual input and the ideal input), $z_{j}$ is the $j$-th environment variable, $\beta^{i}$ represents the corresponding estimate value of each environment variable, and $f^{i} z_{j} ; \beta^{i}$ is the influence of the environment variable. $v_{i j}$ is random error, obeying the normal distribution, $u_{i j}$ is management inefficiency, obeying the truncated normal distribution, and $v_{i j}$ and $u_{i j}$ are independent and irrelevant. The aforementioned SFA regression needs to be calculated as follows:

$$
\begin{gathered}
\gamma=\sigma_{u}^{2} /\left(\sigma_{v}^{2}+\sigma_{u}^{2}\right) \\
\sigma^{2}=\sigma_{v}^{2}+\sigma_{u}^{2}
\end{gathered}
$$

where $\sigma_{u}^{2}$ and $\sigma_{v}^{2}$ represent the variances of the management inefficiency and random error, and $\gamma$ indicates the ratio of the variance of the management inefficiency to the total variance. When $\gamma$ approaches 1, indicating that the technical efficiency of each DMU is different and the stochastic factor is very small, the maximum likelihood method should be used for estimation. When $\gamma$ approaches 0 , indicating that the technical efficiency difference between the decision-making units is not significant and the stochastic difference is large, the maximum square estimation should be used. The estimation results of each parameter are calculated and the input value is adjusted by using the results, so that all of the DMUs are adjusted to the same environmental conditions. The input volume of the other DMU can be adjusted based on the most effective DMU:

$$
\begin{gathered}
x_{i j}^{A}=x_{i j}+\left(\max _{j}\left(z_{j}, \hat{\beta}^{i}\right)-z_{j} \hat{\beta}^{i}\right)+\left(\max _{j}\left\{\hat{v}_{i k}\right\}-\hat{v}_{i k}\right) \\
\hat{E}\left(v_{i j} \mid u_{i j}+u_{i j}\right)=S_{i j}-z_{j} \hat{\beta}^{i}-\hat{E}\left(u_{i j} \mid u_{i j}+u_{i j}\right) \\
\hat{E}\left(u_{i j} \mid u_{i j}+u_{i j}\right)=\frac{\sigma \lambda}{1+\lambda^{2}}\left[\frac{\varphi\left(\varepsilon_{i} \lambda / \sigma\right)}{\Phi\left(\varepsilon_{i} \lambda / \sigma\right)}+\varepsilon_{i} \lambda / \sigma\right]
\end{gathered}
$$

where $\lambda=\sigma_{u} / \sigma_{v}, \varepsilon_{i}=u_{i j}+v_{i j}$ is the joint error term, and $\varphi$ and $\Phi$ represent the density and distribution function of the standard normal distribution, respectively.

\subsubsection{Stage Three}

After using the adjusted input variable to measure the efficiency of each DMU again, the efficiency has no influence on environment and stochastic factors [34,35]. This paper argues that an effective DMU also needs to filter out the effects of environment and stochastic factors, thus allowing re-evaluation of the effectiveness of its management.

\subsection{Index System of Environmental Factors}

\subsubsection{Construction of Index System}

With continuous economic development and societal progress, the demand for water and energy has reached an unprecedented height; this is reflected in all aspects of the four factors (resources, society, economy, and ecological environment). Therefore, based on the relevant research [36,37], this study constructed an index system of environmental factors composed of 48 basic indicators (Table 1) that affects the coupling effect between water and energy and quantifies the influence of this external environment with regard to the four factors as the explanatory variables in Stage two (Equation (4)).

\subsubsection{Processing of Indexes}

In the influence factor frame, each index unit and degree of importance is different, so the subjective and objective combination method was used to process the influence factor data. The subjective and 
objective weights were evaluated by the Analytic Hierarchy Process (AHP) and the entropy method, respectively, and the comprehensive weights were based on D-S evidence synthesis theory [38-43]. According to the calculation above, the corresponding weights of each method can be obtained from Table 1.

Table 1. Index system of environmental factors.

\begin{tabular}{|c|c|c|c|}
\hline Environment Variables & Secondary Indicators & Third Level Indicators & Weight \\
\hline \multirow{13}{*}{ Resource Environment } & \multirow{3}{*}{$\begin{array}{l}\text { Water Resources Development } \\
\text { and Utilization }\end{array}$} & Water resources per capita & 0.0912359 \\
\hline & & Water consumption per unit of GDP * & 0.0052151 \\
\hline & & Water resources development and utilization degree & 0.3052488 \\
\hline & \multirow{3}{*}{ Energy consumption } & Per capita electricity consumption & 0.0076327 \\
\hline & & Electricity consumption per unit of GDP * & 0.0105545 \\
\hline & & Proportion of coal consumption * & 0.030139 \\
\hline & \multirow{2}{*}{ Energy Investment } & Energy industry investment & 0.0754953 \\
\hline & & Waste gas management investment & 0.1317343 \\
\hline & \multirow{2}{*}{ Sewage Treatment } & Total amount of sewage treatment & 0.2060739 \\
\hline & & Rate of urban sewage treatment & 0.0406663 \\
\hline & \multirow{3}{*}{ Utilization Efficiency } & Energy intensity * & 0.0164427 \\
\hline & & Industrial effluent discharge rate & 0.022869 \\
\hline & & Comprehensive utilization ratio of industrial solid waste & 0.0566923 \\
\hline \multirow{10}{*}{ Social Environment } & \multirow{2}{*}{ Population Growth } & Natural growth rate of population * & 0.0089249 \\
\hline & & Population density * & 0.0118809 \\
\hline & \multirow{2}{*}{ Urban-rural Structure } & Urban-rural population ratio & 0.095739 \\
\hline & & Urbanization level & 0.0290601 \\
\hline & \multirow{2}{*}{ Social Security } & Urban registration unemployment rate ${ }^{*}$ & 0.0160734 \\
\hline & & Comparative labor productivity & 0.1098623 \\
\hline & \multirow{2}{*}{ Public Service } & Local general public budget expenditure & 0.1073178 \\
\hline & & Industrial adjustment coefficient & 0.0835815 \\
\hline & Science \& Technology & Per capita education outlay & 0.0626544 \\
\hline & Education & R\&D expenditure ratio & 0.4749056 \\
\hline \multirow{11}{*}{ Economic Environment } & Economic Growth & Annual GDP growth rate & 0.0301135 \\
\hline & \multirow{2}{*}{ Economic Development } & Per capita disposable income of urban residents & 0.1391604 \\
\hline & & Per capita disposable income of rural residents & 0.1422021 \\
\hline & \multirow{2}{*}{ Economic Scale } & Per capita GDP & 0.0683624 \\
\hline & & Stock of per capita fixed assets & 0.0593269 \\
\hline & \multirow{2}{*}{ Economic Structure } & Proportion of the secondary industry & 0.0551652 \\
\hline & & Proportion of the tertiary industry & 0.0988244 \\
\hline & \multirow{2}{*}{ Economic Benefit } & Secondary industry contribution rate & 0.0610254 \\
\hline & & Tertiary industry contribution rate & 0.1267039 \\
\hline & \multirow{2}{*}{ Economic Extraversion } & Per capita FDI & 0.0755002 \\
\hline & & Dependence on foreign trade & 0.1436155 \\
\hline \multirow{14}{*}{ Ecological Environment } & \multirow{2}{*}{ Basic Facilities } & Per capita public green space area & 0.0495535 \\
\hline & & Proportion of nature reserve & 0.0670543 \\
\hline & Manpower Input & Proportion of environmental workers & 0.1347224 \\
\hline & \multirow{3}{*}{ Ecological Scale } & Greenbelt coverage of built-up area & 0.0458514 \\
\hline & & Per capita green space coverage & 0.1379591 \\
\hline & & Forest coverage rate & 0.1999812 \\
\hline & \multirow{5}{*}{ Pollutant Emission } & Carbon emission intensity per unit of GDP * & 0.0103709 \\
\hline & & Sulfur dioxide emission intensity per unit of GDP * & 0.0139201 \\
\hline & & Industrial waste gas emission per unit of GDP * & 0.0105777 \\
\hline & & Per capita carbon emission * & 0.0178669 \\
\hline & & Total industrial effluent discharge * & 0.0189 \\
\hline & \multirow{3}{*}{ Policy Planning } & Environmental investment in GDP & 0.120236 \\
\hline & & Sewage charges accounted for revenue & 0.1400109 \\
\hline & & Per capita sewage charges & 0.0329955 \\
\hline
\end{tabular}

Note: * marked for the reverse indicator. Limited by space, only the comprehensive weights are shown.

\subsection{Data Sources and Processing}

This study assessed China's provinces, municipalities, and autonomous regions (excluding Hong Kong, Macao, and Taiwan); due to a serious lack of relevant data in Tibet, this region was also not included. The input indexes were capital stock calculated from the Perpetual Inventory Method 
(PIM) [43], employment personnel, water footprint [44,45], and energy consumption, representing capital, manpower, water resources, and energy resources, respectively. Output indicators included desirable and undesirable outputs. The selected desirable output was the regional GDP, using the base period of 2003 as the GDP deflator to reduce its value to eliminate the impact of price factors. The undesirable outputs were regional carbon emissions and the grey-water ecological footprint, which were calculated according to the methods of IPCC2006 [46] and the virtual water content at home and abroad respectively [45]. Other data were derived from the China Statistical Yearbook, China Water Resources Bulletin, China Energy Statistical Yearbook, China Grain Yearbook, and China Statistical Yearbook on Environment in each year, as well as the Provincial57 Statistical Yearbook.

\section{Results and Discussion}

\subsection{Stage One}

In the first stage, based on the SBM-DEA model, we used MaxdeaUltra software to obtain the Water-Energy coupling efficiency values before excluding environmental and stochastic factors (Table 2).

Table 2. The Water-Energy coupling efficiency in various areas of China before adjustment.

\begin{tabular}{|c|c|c|c|c|c|}
\hline Region & 2003 & 2007 & 2011 & 2015 & Average \\
\hline \multicolumn{6}{|c|}{ East } \\
\hline Beijing & 1 & 1 & 1 & 1 & 1 \\
\hline Tianjin & 1 & 1 & 1 & 1 & 1 \\
\hline Hebei & 0.446141 & 0.446442 & 0.434448 & 0.383724 & 0.430407 \\
\hline Shanghai & 0.306585 & 0.37508 & 0.443222 & 0.412682 & 0.390732 \\
\hline Jiangsu & 0.309984 & 0.316796 & 0.37809 & 0.360684 & 0.34406 \\
\hline Zhejiang & 0.586479 & 0.5199 & 0.552559 & 0.535031 & 0.544582 \\
\hline Fujian & 0.548022 & 0.569936 & 0.60875 & 0.592826 & 0.582367 \\
\hline Shandong & 0.469097 & 0.37655 & 0.337597 & 0.319929 & 0.363234 \\
\hline Guangdong & 1 & 1 & 1 & 1 & 1 \\
\hline Hainan & 1 & 1 & 1 & 1 & 1 \\
\hline Average & 0.666631 & 0.66047 & 0.675467 & 0.660488 & 0.665538 \\
\hline \multicolumn{6}{|c|}{ Northeast } \\
\hline Liaoning & 1 & 1 & 1 & 1 & 0.98813 \\
\hline Jilin & 0.469135 & 0.471483 & 0.479159 & 0.487041 & 0.479822 \\
\hline Heilongjiang & 1 & 0.815573 & 0.758264 & 0.800654 & 0.807001 \\
\hline Average & 0.823045 & 0.762352 & 0.745808 & 0.762565 & 0.758318 \\
\hline \multicolumn{6}{|c|}{ Central Areas } \\
\hline Shanxi & 0.547697 & 0.576414 & 0.616397 & 0.591138 & 0.591323 \\
\hline Anhui & 0.60685 & 0.663972 & 0.588314 & 0.611378 & 0.627385 \\
\hline Jiangxi & 0.420899 & 0.438451 & 0.422452 & 0.47054 & 0.438989 \\
\hline Henan & 0.504259 & 0.434349 & 0.41688 & 0.505749 & 0.459025 \\
\hline Hubei & 0.426506 & 0.440985 & 0.461889 & 0.503999 & 0.455642 \\
\hline Hunan & 1 & 1 & 1 & 1 & 1 \\
\hline Average & 0.584369 & 0.592362 & 0.584322 & 0.613801 & 0.595394 \\
\hline \multicolumn{6}{|c|}{ West } \\
\hline Chongqing & 0.590795 & 0.573126 & 0.641648 & 0.755155 & 0.624126 \\
\hline Sichuan & 0.36526 & 0.397335 & 0.411907 & 0.476396 & 0.410645 \\
\hline Guizhou & 0.373881 & 0.410142 & 0.495629 & 0.61219 & 0.462443 \\
\hline Yunnan & 0.447861 & 0.449602 & 0.433184 & 0.467562 & 0.452524 \\
\hline Shaanxi & 0.477918 & 0.527668 & 0.5667 & 0.534536 & 0.540191 \\
\hline Gansu & 0.479837 & 0.49853 & 0.491934 & 0.512617 & 0.495641 \\
\hline Qinghai & 1 & 1 & 1 & 1 & 1 \\
\hline Ningxia & 1 & 1 & 1 & 1 & 1 \\
\hline Xinjiang & 0.591016 & 0.548447 & 0.544524 & 0.470137 & 0.537942 \\
\hline Guangxi & 1 & 1 & 1 & 1 & 1 \\
\hline $\begin{array}{c}\text { Inner } \\
\text { Mongolia }\end{array}$ & 0.463954 & 0.446641 & 0.396282 & 0.37126 & 0.417249 \\
\hline Average & 0.61732 & 0.622863 & 0.63471 & 0.654532 & 0.630978 \\
\hline
\end{tabular}

Note: Limited by space, only the 2003, 2007, 2011, and 2015 values and the 2003-2015 average are shown.

As can be seen from Table 2, eight provinces and cities achieved an efficient level of Water-Energy coupling. Among the other provinces and cities, Liaoning Province had the highest average coupling 
efficiency (0.98813) while Jiangsu Province had the lowest average coupling efficiency value (0.34406). As shown in Figure 1, the efficiency values of coupling efficiency were relatively high in China. Most values were higher than 0.5 , and the average efficiency values in the east, northeast, middle, and west were $0.665538,0.758318,0.595394$, and 0.630978 , respectively, showing a spatial distribution ranking from northeast $>$ east $>$ west $>$ central.

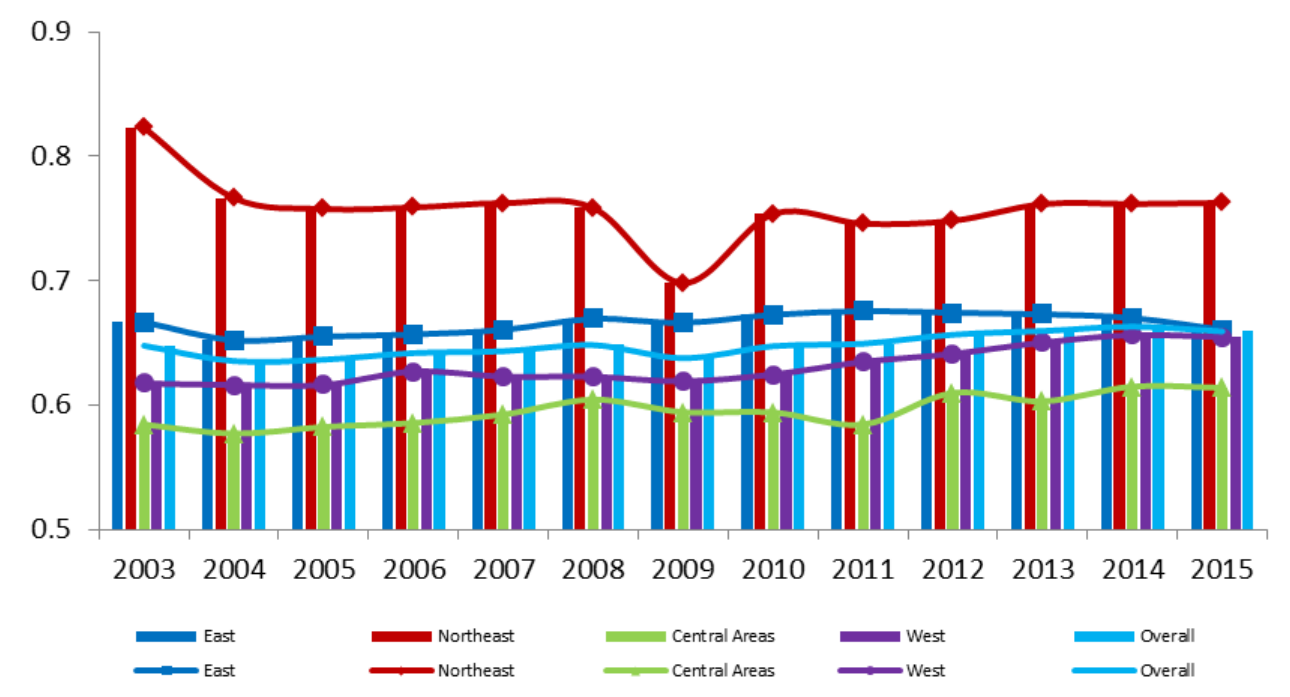

Figure 1. Vertical bars and trend lines show the regional Water-Energy coupling efficiency (left axis), $2003-2015$.

From the evolution trend of the efficiency in the four regions during the sample period (Figure 1), the Water-Energy coupling efficiency from 2003-2015 was basically unchanged. The main reason for this lack of change is the rapid expansion of investment in high-energy industries during the "Eleventh Five-year Plan", which accelerated the consumption of water and energy and carbon dioxide emissions. Meanwhile, binding targets for energy saving and emission reduction were put forward. Furthermore, the "Twelfth Five-year Plan" put forward the goal of reducing energy consumption by $16 \%$ and carbon dioxide emissions GDP by $17 \%$, so the country is on the road toward low-carbon economic development. It is worth noting that because of the eruption of the 2008 global economic crisis, the Chinese government increased investment to expand domestic demand, resulting in a slight decline in 2009. After that, due to the gradual digestion of this investment, the guidance and driving role of the Chinese government continued to promote rising efficiency.

\subsection{Stage Two}

The second stage implemented Frontier 4.0 to isolate environmental factors, stochastic noise, and management inefficiency. The gamma value in Table 3 is greater than 0.80 , indicating that the use of the SFA was reasonable, and the table shows that the input slack volume likelihood ratio (LR) test results of $297.90895,621.05,864.89$, and 457.7 were located outside of the $99 \%$ confidence interval; therefore, management inefficiency actually exists. When the regression coefficient is negative, this indicates that an increase in the environment variable will decrease the slack amount of the input variable, that is, the environment variable has a positive effect on the input variable and vice versa.

The coefficients of slack of resource environment and social environment for all inputs were negative and significant at $1 \%$, indicating that the resource environment and social environment had positive effects on all inputs. Therefore, they had significant effects on the four inputs of the coupling relationship between water and energy, but the social environment's influence was not as large as that of the resource environment. Because of complex external factors, the economic environment and ecological environment were more vulnerable to political factors and international factors. The economic environment was positive for the slack of capital stock, employment personnel, and water footprint, indicating that the economic environment was not conducive to narrowing 
the gap between the three inputs and the ideal inputs. At the same time, the coefficient for energy consumption was negative, indicating that the economic environment had a positive effect on energy consumption. The ecological environment was positive for the water footprint, but negative for capital stock, employment personnel, and energy consumption. Although some variables were not significant, they still had directional effects.

Table 3. Stochastic Frontier Approach (SFA) regression results.

\begin{tabular}{|c|c|c|c|c|}
\hline Variable & Capital Stock & Employment Personnel & Water Footprint & $\begin{array}{c}\text { Energy } \\
\text { Consumption }\end{array}$ \\
\hline Constant & $\begin{array}{l}-3152.161^{* * *} \\
(-3149.5018)\end{array}$ & $\begin{array}{c}-3546.4536^{* * *} \\
(-156.87411)\end{array}$ & $\begin{array}{c}-478.55315^{* * *} \\
(-13.050275)\end{array}$ & $\begin{array}{c}-6606.4096^{* * *} \\
(-3731.2915)\end{array}$ \\
\hline $\begin{array}{c}\text { Resources } \\
\text { Environment }\end{array}$ & $\begin{array}{c}-46470.535^{* * *} \\
(-46469.252)\end{array}$ & $\begin{array}{l}-251.18285 * * * \\
(-37.149723)\end{array}$ & $\begin{array}{c}-561.73942 * * * \\
(-5.1765442)\end{array}$ & $\begin{array}{c}-20275.529 * * * \\
(-18478.819)\end{array}$ \\
\hline $\begin{array}{c}\text { Social } \\
\text { Environment }\end{array}$ & $\begin{array}{c}-9283.5029 * * * \\
(-9283.4855)\end{array}$ & $\begin{array}{c}-230.71714^{* * *} \\
-45.301469)\end{array}$ & $\begin{array}{c}-412.68387^{* * *} \\
(-2.9321697)\end{array}$ & $\begin{array}{c}-4020.0156^{* * *} \\
(-3391.4211)\end{array}$ \\
\hline $\begin{array}{c}\text { Economic } \\
\text { Environment }\end{array}$ & $\begin{array}{l}13604.762 * * * \\
(-13604.579)\end{array}$ & $\begin{array}{l}2740.9118^{* * *} \\
(-345.04024)\end{array}$ & $\begin{array}{c}94.849516^{* *} \\
(-0.76725493)\end{array}$ & $\begin{array}{c}-1224.8368^{* * *} \\
(-955.45612)\end{array}$ \\
\hline $\begin{array}{c}\text { Ecological } \\
\text { Environment }\end{array}$ & $\begin{array}{l}13847.54 * * * \\
(-13847.468)\end{array}$ & $\begin{array}{l}2881.5491 * * * \\
(-314.55491)\end{array}$ & $\begin{array}{l}-229.24258^{* *} \\
(-2.2052833)\end{array}$ & $\begin{array}{l}19595.257 * * * \\
(-13741.142)\end{array}$ \\
\hline $\begin{array}{c}\text { Sigma-squared } \\
\text { Gamma } \\
\text { Log Likelihood }\end{array}$ & $\begin{array}{c}51907495 * * * \\
0.85977245 \\
-3716.7\end{array}$ & $\begin{array}{c}2058250.9^{* * *} \\
0.94168732 \\
-2896.6202\end{array}$ & $\begin{array}{c}132495.73^{* * *} \\
0.9725617 \\
-2239.7968\end{array}$ & $\begin{array}{c}31297354^{* * *} \\
0.92094702 \\
-3518.2246\end{array}$ \\
\hline $\begin{array}{l}\text { LR Test of the } \\
\text { One-sided Error }\end{array}$ & 297.90895 & 621.05406 & 864.886 & 457.70496 \\
\hline
\end{tabular}

To summarize, the resource, social, economic, and ecological environment variables selected in this paper had different and significant influences on the slack amount invested by various DMUs, so the original input variables must be adjusted by excluding the influence of the external environment and stochastic factors to reflect the real Water-Energy coupling efficiency level. Using the parameter estimate obtained from the second stage, the coupling efficiency in various provinces and cities was adjusted (Table 4 ).

Table 4. Water-Energy coupling efficiency in various areas of China after adjustment.

\begin{tabular}{cccccc}
\hline Region & $\mathbf{2 0 0 3}$ & $\mathbf{2 0 0 7}$ & $\mathbf{2 0 1 1}$ & $\mathbf{2 0 1 5}$ & Average \\
\hline \multicolumn{7}{c}{ East } \\
Beijing & 1 & 1 & 1 & 1 & 1 \\
Tianjin & 1 & 1 & 1 & 1 & 1 \\
Hebei & 0.226933 & 0.186492 & 0.168631 & 0.154293 & 0.181516 \\
Shanghai & 0.304882 & 0.306125 & 0.318688 & 0.291432 & 0.305996 \\
Jiangsu & 0.232677 & 0.174279 & 0.152818 & 0.139388 & 0.171057 \\
Zhejiang & 0.306924 & 0.242941 & 0.234446 & 0.234086 & 0.25264 \\
Fujian & 0.421175 & 0.39593 & 0.378679 & 0.353577 & 0.385727 \\
Shandong & 0.231138 & 0.186631 & 0.155889 & 0.139896 & 0.176895 \\
Guangdong & 1 & 1 & 0.392163 & 0.352248 & 0.712351 \\
Hainan & 1 & 1 & 1 & 1 & 1 \\
\hline Average & 0.572373 & 0.54924 & 0.480131 & 0.466492 & 0.518618 \\
\hline \multicolumn{7}{c}{ Northeast } & & \\
\hline Liaoning & 1 & 1 & 0.394179 & 0.400998 & 0.628468 \\
Jilin & 0.405377 & 0.36132 & 0.330218 & 0.344393 & 0.358329 \\
Heilongjiang & 1 & 0.412573 & 0.296262 & 0.305602 & 0.410953 \\
\hline Average & 0.801792 & 0.591298 & 0.34022 & 0.350331 & 0.465916 \\
\hline
\end{tabular}


Table 4. Cont.

\begin{tabular}{cccccc}
\hline Region & $\mathbf{2 0 0 3}$ & $\mathbf{2 0 0 7}$ & $\mathbf{2 0 1 1}$ & $\mathbf{2 0 1 5}$ & Average \\
\hline \multicolumn{5}{c}{ Central Areas } \\
\hline Shanxi & 0.345204 & 0.304061 & 0.296496 & 0.299518 & 0.308401 \\
Anhui & 0.363937 & 0.349059 & 0.291439 & 0.289854 & 0.332571 \\
Jiangxi & 0.362591 & 0.309679 & 0.282745 & 0.284424 & 0.308107 \\
Henan & 0.27449 & 0.210265 & 0.186054 & 0.179333 & 0.208293 \\
Hubei & 0.286587 & 0.234835 & 0.199355 & 0.218635 & 0.2333 \\
Hunan & 1 & 1 & 1 & 1 & 1 \\
\hline Average & 0.438802 & 0.401317 & 0.376015 & 0.378627 & 0.398445 \\
\hline \multicolumn{7}{c}{ West } \\
Chongqing & 0.504823 & 0.491885 & 0.460293 & 0.524644 & 0.485913 \\
Sichuan & 0.262284 & 0.224419 & 0.210418 & 0.24184 & 0.22646 \\
Guizhou & 0.414967 & 0.403945 & 0.432617 & 0.433432 & 0.419114 \\
Yunnan & 0.405532 & 0.357551 & 0.327963 & 0.316444 & 0.35049 \\
Shaanxi & 0.41747 & 0.395588 & 0.373137 & 0.33569 & 0.381908 \\
Gansu & 0.505652 & 0.462924 & 0.434843 & 0.434061 & 0.455734 \\
Qinghai & 1 & 1 & 1 & 1 & 1 \\
Ningxia & 1 & 1 & 1 & 1 & 1 \\
Xinjiang & 0.504206 & 0.456466 & 0.427971 & 0.346225 & 0.433065 \\
Guangxi & 1 & 1 & 1 & 1 & 1 \\
Inner & 0.330707 & 0.239329 & 0.180736 & 0.18056 & 0.222783 \\
Mongolia & & 0.548373 & 0.531634 & 0.528445 & 0.543224 \\
\hline Average & 0.576876 & 0.548373
\end{tabular}

Note: Limited by space, the 2003, 2007, 2011, and 2015 values and the 2003-2015 average are shown.

\subsection{Stage Three}

Based on the results of the third stage (Table 4, Figure 2), the coupling efficiency was greatly changed after stripping the external environment and random error effects on the Water-Energy coupling efficiency. The coupling level of water and energy in China was in a steady state before stripping, but afterward, the coupling efficiency declined to various degrees. The provincial and municipal rankings changed compared with the pre-stripping results. The most efficient and most stable were Beijing, Tianjin, Hunan, Guangxi, Hainan, Qinghai, and Ningxia; other provinces had varying degrees of efficiency decline. Lower efficiency values indicated that the technical management level of these provinces and cities was not very high. Because some of these provinces and cities have been in a strong external environment, there has not been much focus on improving the management level. For other provinces and cities, although some regional strategies have adopted a follow-up approach, the efficiency values of coupling water and energy were not as good as expected without considering local realities or the lag in technological innovation inputs. We can conclude that the management level of each province has had a significant effect on the coupling efficiency of its water and energy and that the degree of influence varies according to the specific environment of each province.

After eliminating the impacts of environmental variables and random factors, the regional efficiency values were reduced to different degrees (Figure 3). Due to the favourable external environment of the northeast and the impact of the 2008 economic crisis, the efficiency of the northeast region declined sharply compared with that of the eastern region. The other two regions, although their efficiency values decreased, were in a relatively stable state. The western region remained particularly steady while the middle region maintained a low level with a stable trend; this indicates that the economic crisis had less impact on these regions, so we can conclude that external environment and management level are the main factors restricting their development. Due to the development of the western region via national policy, its management level increased to a certain degree, and the efficiency values of the eastern and northeastern regions were even lower than that of the western region after 2008. 


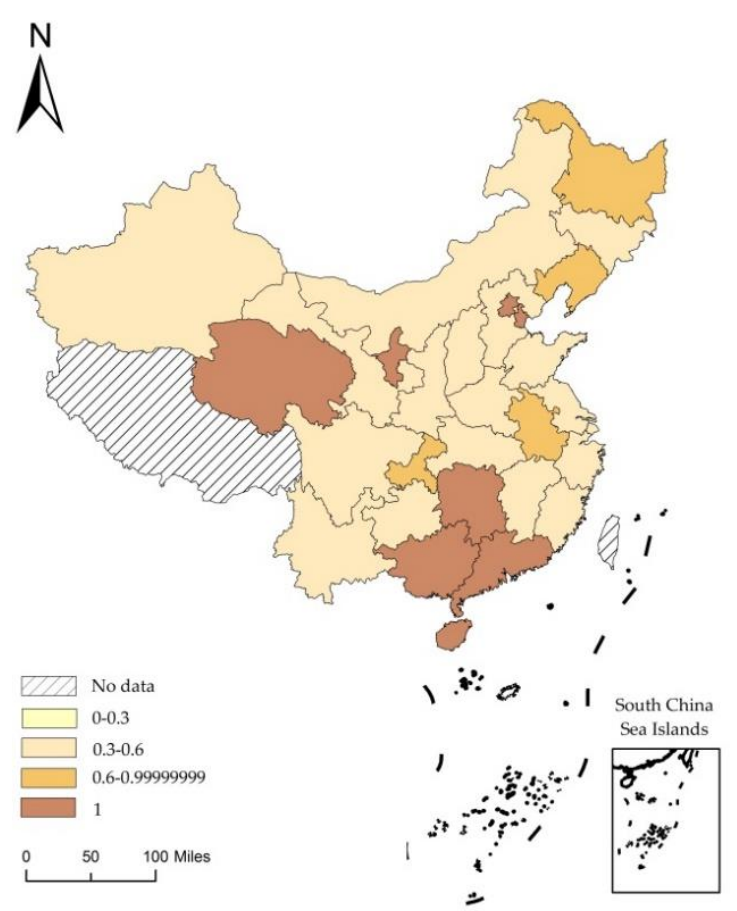

Before Adjustment

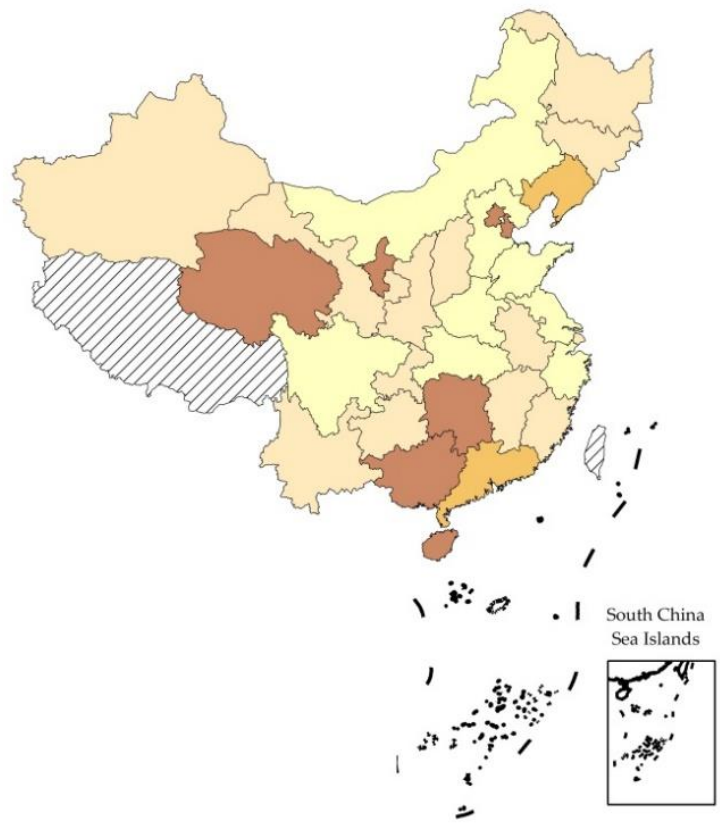

After Adjustment

Figure 2. Average Water-Energy coupling efficiency for 2003-2015 in China before and after adjustment for external environmental and random factors. (Source data is shown in Appendix A, Table A1).

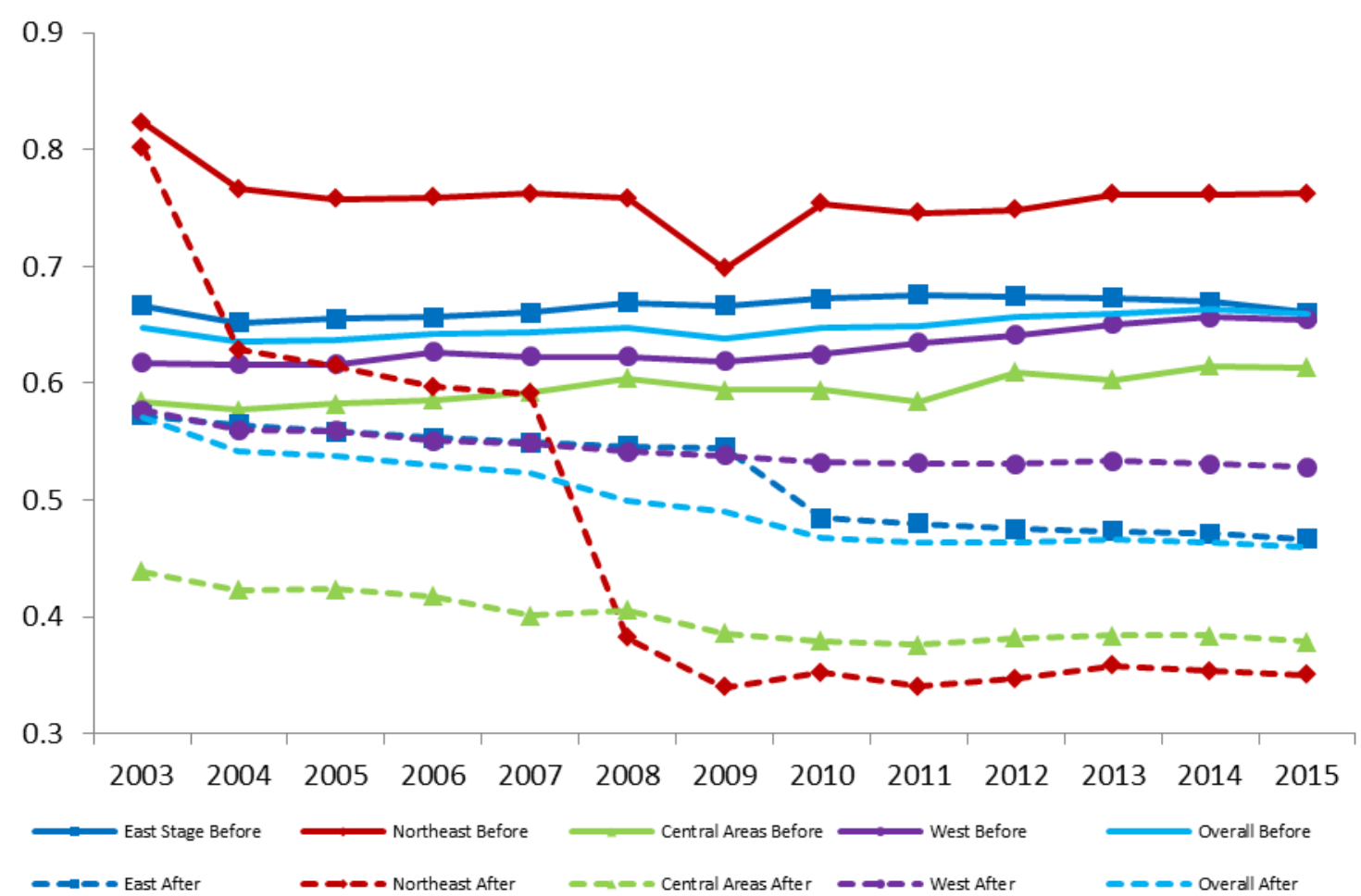

Figure 3. Trend lines of regional Water-Energy coupling efficiency before and after adjustment, 2003-2015.

\section{Conclusions and Suggestions}

This study combined the SBM-DEA model with the SFA method to construct an index system of environmental factors and a three-stage calculation model of Water-Energy coupling efficiency in 
30 provincial districts in China from 2003-2015. The traditional DEA model does not take into account the influences of environmental factors and random noise on the efficiency evaluation of the DMU [25]. And it is necessary to isolate these factors through SFA regression model to constructe an index an index of environmental factors that affect the Water-Energy coupling efficiency from the four aspects of resource environment, social environment, economic environment, and ecological environment. In the second stage, the external environmental factors and stochastic factors are further removed, which results in DMU input redundancy by only management inefficiency [34]. After removing the external environmental factors and stochastic factors, this paper measured the efficiency of each DMU again; the efficiency of stage three just reflects efficiency under the current management implications. This method can overcome the decision bias caused by the radial and angled DEA, and can also eliminate the influence of external environment and stochastic factors on efficiency evaluation. The empirical results can provide enough valid bases to judge the pros and cons of the DEA method in the performance evaluation. The results of the study are as follows.

(1) In the first stage, we used the SBM model to determine that the Water-Energy coupling efficiency in China was relatively high and stable, with a spatial ranking from northeast $>$ east $>$ west $>$ central. However, after rejecting the influences of external environment and random factors and using the SBM model again, we determined that the efficiency values of each region declined to different degrees over time and that the efficiency values in the north-east declined more sharply year by year. The comparison results showed that the management policy of the coupling level of water and energy in China is not comprehensive enough and improving the management level would be an effective way to improve the Water-Energy coupling efficiency. The coupling efficiency of water and energy in China currently depends on a favorable external environment, and China's management level of technological and institutional innovation still has some space for improvement.

(2) After the SFA regression in the second stage, it was showed that the resource environment and social environment had significant positive impacts on all inputs. In the meantime, the increase in the proportion of the economic and ecological environments was not conducive to narrowing the gap between all inputs and the ideal inputs, but the increase of the proportion of the economic environment was helpful for reducing the slack of energy consumption and the ecological environment had a positive impact on water footprint investment.

Given the goals of guaranteeing steady growth in China's economy and the continuous progress of its society, this study offers the following suggestions to improve the coupling efficiency of water and energy to realize water safety, energy security and sustainable development based on an empirical analysis of the regional differences of water and energy coupling efficiency.

The level of technology management in China should be improved, emphasizing management and system innovation. Because of the influence of the external environment on the Water-Energy coupling efficiency, China should maintain and improve this factor and continue to upgrade industrial infrastructure, vigorously develop low-energy and high value-added industries, and further optimise the consumption structure of water and energy to ensure sustainable development. For areas in an unfavourable external environment, scientific and technological expenditures should be increased and funds reasonably allocated for scientific research toward improving the Water-Energy coupling efficiency by leveraging the higher level of resource utilization brought by talent and advanced technology.

In the process of formulating relevant management policies, China should also pay attention to the rationalization of allocations between elements and consider differences in the internal management efficiency of the four regions. Above all, a differentiated management policy should be developed according to the objective reality of each region to best realize sustainable development within the entire country.

Author Contributions: M.W., C.S. and X.W. produced the paper and all co-authors contributed to the data collection and calculations. 
Funding: This article has been funded by the Key Program of the Chinese National Social Science Foundation (No. 16AJY009).

Acknowledgments: The authors are grateful to the anonymous referees who provided valuable comments and suggestions to significantly improve the quality of the paper. English language editing was provided by Editage (http://www.editage.cn/).

Conflicts of Interest: The authors declare no conflict of interest.

\section{Appendix A}

Table A1. Comparison of average Water-Energy coupling efficiency for 2003-2015 in China (source data for Figure 2).

\begin{tabular}{ccc}
\hline Regions & Before Adjustment & After Adjustment \\
\hline Beijing & 1 & 1 \\
Tianjin & 1 & 1 \\
Hebei & 0.430407 & 0.181516 \\
Shanxi & 0.591323 & 0.308401 \\
Inner Mongolia & 0.417249 & 0.222783 \\
Liaoning & 0.98813 & 0.628468 \\
Jilin & 0.479822 & 0.358329 \\
Heilongjiang & 0.807001 & 0.410953 \\
Shanghai & 0.390732 & 0.305996 \\
Jiangsu & 0.34406 & 0.171057 \\
Zhejiang & 0.544582 & 0.25264 \\
Anhui & 0.627385 & 0.332571 \\
Fujian & 0.582367 & 0.385727 \\
Jiangxi & 0.438989 & 0.308107 \\
Shandong & 0.363234 & 0.176895 \\
Henan & 0.459025 & 0.208293 \\
Hubei & 0.455642 & 0.2333 \\
Hunan & 1 & 1 \\
Guangdong & 1 & 0.712351 \\
Guangxi & 1 & 1 \\
Hainan & 1 & 1 \\
Chongqing & 0.624126 & 0.485913 \\
Sichuang & 0.410645 & 0.22646 \\
Guizhou & 0.462443 & 0.419114 \\
Yunnan & 0.452524 & 0.35049 \\
Shaanxi & 0.540191 & 0.381908 \\
Gansu & 0.495641 & 0.455734 \\
Qinghai & 1 & 1 \\
Ningxia & 1 & 0.433065 \\
Xinjiang & 0.537942 & \\
\hline
\end{tabular}

\section{References}

1. International Energy Agency (IEA). World Energy Outlook 2016; International Energy Agency: Paris, France, 2016.

2. UNESCO. The United Nations World Water Development Report 2: Water, a Shared Responsibility; UNESCO: Paris, France, 2006.

3. Schnoor, J.L. Water-Energy nexus. Environ. Sci. Technol. 2011, 45, 5065. [CrossRef]

4. Cai, J.L. Impacts of urbanization on water use and energy-related $\mathrm{CO}_{2}$ emissions of residential consumption in China: A spatio-temporal analysis during 2003-2012. J. Clean. Prod. 2018, 194, 23-33. [CrossRef]

5. Li, K.; Fang, L.; He, L. How urbanization affects China's energy efficiency: A spatial econometric analysis. J. Clean. Prod. 2018, 200, 1130-1141. [CrossRef]

6. Hong, S.Y.; Wang, H.R.; Lai, E.L.; Zhu, Z.F. Spatial analysis and coordinated development decoupling analysis of energy-consumption water in China. J. Nat. Resour. 2017, 32, 800-813. [CrossRef]

7. Pei, Y.J.; Song, W.W.; Shi, J.W.; Pang, H. Flow field and strength analysis of composite space guide blade structure of inclined flow pump. Water Resour. Power 2017, 6, 40.

8. Jiang, S. Scientific Concept of Water-Energy Nexus and Coupling Simulation; China Institute of Water Conservancy and Hydropower Science: Beijing, China, 2017. 
9. Hamiche, A.M.; Stambouli, A.B.; Flazi, S. A review of the Water-Energy nexus. Renew. Sustain. Energy Rev. 2016, 65, 319-331. [CrossRef]

10. Bertrand, A.; Mastrucci, A.; Schüler, N.; Aggoune, R.; Maréchal, F. Characterisation of domestic hot water end-uses for integrated urban thermal energy assessment and optimisation. Appl. Energy 2017, 186, 152-166. [CrossRef]

11. DeNooyer, T.A.; Peschel, J.M.; Zhang, Z.; Stillwell, A.S. Integrating water resources and power generation: The energy-water nexus in Illinois. Appl. Energy 2016, 162, 363-371. [CrossRef]

12. Topi, C.; Esposto, E.; Govigli, V.M. The economics of green transition strategies for cities: Can low carbon, energy efficient development approaches be adapted to demand side urban water efficiency? Environ. Sci. Policy 2016, 58, 74-82. [CrossRef]

13. Scott, C.A.; Pierce, S.A.; Pasqualetti, M.J.; Jones, A.L.; Montz, B.E.; Hoover, J.H. Policy and institutional dimensions of the Water-Energy nexus. Energy Policy 2011, 39, 6622-6630. [CrossRef]

14. Pacetti, T.; Lombardi, L.; Federici, G. Water-Energy nexus: A case of biogas production from energy crops evaluated by Water Footprint and Life Cycle Assessment (LCA) methods. J. Clean. Prod. 2015, 101, 278-291. [CrossRef]

15. Ewing, B.R.; Hawkins, T.R.; Wiedmann, T.O.; Galli, A.; Ercin, A.E.; Weinzettel, J.; Steen-Olsen, K. Integrating ecological and water footprint accounting in a multi-regional input-output framework. Ecol. Indic. 2012, 23, 1-8. [CrossRef]

16. Dale, L.L.; Dale, L.L.; Karali, N.; Millstein, D.; Carnall, M.; Vicuña, S.; Borchers, N.; Bustos, E.; O’Hagan, J.; Purkey, D.; Heaps, C.; et al. An integrated assessment of water-energy and climate change in Sacramento, California: How strong is the nexus? Clim. Chang. 2015, 132, 223-235. [CrossRef]

17. Wang, W.H.; Tang, X.; Yang, X.G. Energy savings in China's energy sectors and contributions to air pollution reduction in the 12th Five Year Plan. J. Clean. Prod. 2018, 200, 305-317. [CrossRef]

18. Wang, W.R.; Zhang, L.L. Water resources allocation analysis in the context of the strictest water resources management system. Hydroelectr. Energy Sci. 2014, 32, 38-41.

19. Fan, J.L.; Hu, J.W.; Kong, L.S.; Zhang, X.H. Relationship between energy production and water resource utilization: A panel data analysis of 31 provinces in China. J. Clean. Prod. 2017, 167, 88-96. [CrossRef]

20. Zhu, X.; Guo, R.P.; Chen, B.; Zhang, J.; Tasawar, H.; Ahmed, A. Embodiment of virtual water of power generation in the electric power system in China. Appl. Energy 2015, 151, 110-121. [CrossRef]

21. Zhou, Y.; Zhang, B.; Wang, H.K.; Bi, J. Drops of energy: Conserving urban water to reduce greenhouse gas emissions. Environ. Sci. Technol. 2013, 47, 10753-10761. [CrossRef]

22. Duan, C.; Chen, B. Energy-water nexus of international energy trade of China. Appl. Energy 2016, 194, 725-734. [CrossRef]

23. Wang, S.; Chen, B. Energy-water nexus of urban agglomeration based on multiregional input-output tables and ecological network analysis: A case study of the Beijing-Tianjin-Hebei region. Appl. Energy 2016, 178, 773-783. [CrossRef]

24. Zhang, J.; Bu, S. Measuring allocation efficiency of regional green S\&T resources based on three-stage SBM-DEA-Taking Guilin City as an example. Resour. Dev. Mark. 2017, 33, 1-7. [CrossRef]

25. Fried, H.O.; Lovell, C.A.K.; Schmidt, S.S.; Yaisawarng, S. Accounting for environmental effects and statistical noise in data envelopment analysis. J. Product. Anal. 2002, 17, 157-174. [CrossRef]

26. Aigner, D.; Lovell, C.A.K.; Schmidt, S.S. Formulation and estimation of stochastic frontier production function models. J. Econom. 1977, 6, 21-37. [CrossRef]

27. Zhang, J.; Li, H.; Xia, B.; Skitmore, M. Impact of environment regulation on the efficiency of regional construction industry: A 3-stage Data Envelopment Analysis (DEA). J. Clean. Prod. 2018, 200, 770-780. [CrossRef]

28. Deng, B.; Zhang, X.J.; Guo, J.H. Research on ecological efficiency based on three-stage DEA model. China Soft Sci. 2011, 1, 92-99.

29. Charnes, A.; Cooper, W.W.; Rhodes, E. Measuring the efficiency of decision making units. Eur. J. Oper. Res. 1978, 2, 429-444. [CrossRef]

30. Liu, J.; Tone, K. A multistage method to measure efficiency and its application to Japanese banking industry. Socio-Econ. Plan. Sci. 2008, 42, 75-91. [CrossRef]

31. Tone, K. A slacks-based measure of efficiency in data envelopment analysis. Eur. J. Oper. Res. 2001, 130, 498-509. [CrossRef] 
32. Chen, W.; Zhang, L.; Ma, T.H.; Liu, W.L. Research on three-stage DEA model. Syst. Eng. 2014, 9, $144-149$.

33. Kumbhakar, S.C.; Lovell, K.C.A. Stochastic Frontier Analysis; Cambridge University Press: Cambridgem, UK, 2000; pp. 136-142.

34. Risto, H.; Rajeev, K.G. Global $\mathrm{CO}_{2}$ efficiency: Country wise estimates using a stochastic cost frontier. Energy Policy 2012, 45, 762-770. [CrossRef]

35. Sun, C.Z.; Zhao, L.S. Water resource utilization efficiency and spatial spillover effects in China. J. Geogr. Sci. 2014, 24, 771-788. [CrossRef]

36. Thiede, S.; Malte, S.; Kurle, D.; Herrmann, C. Multi-level simulation in manufacturing companies: The water-energy nexus case. J. Clean. Prod. 2016, 139, 1118-1127. [CrossRef]

37. Carrasquer, B.; Uche, J.; Amaya, M.G. A new indicator to estimate the efficiency of water and energy use in agro-industries. J. Clean. Prod. 2017, 143, 462-473. [CrossRef]

38. Li, G. A study on the combination of subjective and objective weights and its rationality. Manag. Rev. 2017, 29, 17-26. [CrossRef]

39. Shafer, G. A Mathematical Theory of Evidence; Princeton University Press: Princeton, NJ, USA, 1976; pp. 1-150.

40. Wang, S.; Sun, C.Z.; Li, X.; Zou, W. Sustainable development in China's coastal area: Based on the Driver-Pressure-State-Welfare-Response Framework and the Data Envelopment Analysis Model. Sustainability 2016, 8, 958. [CrossRef]

41. Dempster, A.P. Upper and lower probabilities induced by a multivalued mapping. Ann. Math. Stat. 1967, 38, 325-339. [CrossRef]

42. Dempster, A.P. Generalization of Bayesian inference. J. R. Stat. Soc. 1968, 30, 205-247. [CrossRef]

43. Sun, C.Z.; Wang, X.L.; Wang, S. Measurement and spatial effect analysis of China's biased technology progress under environmental constraints. Econ. Geogr. 2018, 38. [CrossRef]

44. Hoekstra, A.Y.; Chapagian, A.K.; Hoekstra, A.Y.; Mekonnen, M.M. The Water Footprint Assessment Manual; Routledge: London, UK, 2012.

45. Morera, S.; Corominas, L.; Poch, M.; Aldaya, M.M.; Comas, J. Water footprint assessment in wastewater treatment plants. J. Clean. Prod. 2016, 112, 4741-4748. [CrossRef]

46. Eggleston, S.; Buendia, L.; Miwa, K.; Ngara, T.; Tanabe, K. IPCC: National Greenhouse Gas Inventory Guide; Institute of Global Environmental Strategy (IGES): Kanagawa, Japan, 2006. 